\title{
New Estimates for the Price of Housing in the Japanese CPI
}

Chihiro Shimizu, Satoshi Imai and Erwin Diewert ${ }^{1}$

July, 2015

Discussion Paper 15-02,

School of Economics,

University of British Columbia,

Vancouver, B.C.,

Canada, V6N 1 Z1.

Email: erwin.diewert@ubc.ca

\begin{abstract}
The paper looks at problems associated with measuring the services of owner-occupied housing $(\mathrm{OOH})$ in the Japanese CPI. The paper shows that alternative approaches to measuring the services of $\mathrm{OOH}$ lead to quite different measures of CPI inflation for Japan. The Japanese CPI uses a rental equivalence approach to measuring $\mathrm{OOH}$ services and uses an index of all paid rents to price these services. However, Japanese rents are very sticky and under these circumstances, it seems more appropriate to use an index of newly contracted rents to value the opportunity cost of using the services of owned dwelling units. The paper examines this issue. It also looks at the adequacy of the sampling approach used in the Japanese CPI and at the problems surrounding the treatment of depreciation in constructing constant quality indexes for paid rents in the Japanese CPI. Finally, hedonic regressions for the quality adjustment of rents are run on an extensive data set.
\end{abstract}

\section{Journal of Economic Literature Numbers}

E30; R20

\section{Key Words}

housing rent; price rigidity; time-dependent model; state-dependent model; adjustment hazard function; user cost of housing; rental equivalence approach; hedonic regressions.

\footnotetext{
1 The National University of Singapore and the University of British Columbia (email: cshimizu@nus.edu.sg ), Nowcast Co. Ltd., and The University of British Columbia and the University of New South Wales respectively. This paper was presented at the $14^{\text {th }}$ Ottawa Group Meeting in Tokyo on May 21, 2015 and at the $2^{\text {nd }}$ Society for Economic Measurement Meeting in Paris on July 22, 2015. The authors thank David Fenwick, Kevin Fox, Tsutomu Watanabe, Kiyohiko Nishimura and Derek Bird for helpful comments. Diewert thanks the SSHRC of Canada for financial support.
} 


\section{Introduction}

Throughout their histories most advanced nations have experienced abrupt increases and subsequent decreases in asset prices, especially housing prices. These fluctuations have had substantial impact on the financial system. often leading to a stagnation of economic activity. The most representative examples are Japan and Sweden in the 1990s and, more recently, the global financial crisis triggered by the sub-prime problem in the United States. Reinhart and Rogoff (2008) conducted an exhaustive, long-term, comparative time series analysis of economic data from numerous countries which made it clear that the incidence of various economic phenomena is a common factor underlying banking crises. It has been noted that one of these phenomena is a significant increase in asset prices, and property prices in particular, compared to rents. ${ }^{2}$

This raises the following question: why do services prices not fluctuate significantly when asset prices fluctuate? If we consider housing asset prices as being determined based on the net present value of future revenue (rent) that will be produced, housing prices and housing rents should be covariant even if there is a certain lag between them. Moreover, if we assume that consumers choose housing by weighing the cost of investing in housing ${ }^{3}$ versus rental costs, it is difficult to believe that the two would diverge significantly. However, in reality, the two do diverge significantly and the fluctuation of property prices in particular is a factor that has induced many economic problems.

Rent, meanwhile, occupies an important position in the goods and services market and in many countries has a weight in the CPI basket of approximately $25 \%$. ${ }^{4}$ The housing market plays an essential role in both the asset market and the goods and services market, and rent in particular is an important connection point linking asset prices to goods and services prices. ${ }^{5}$

In estimating rental costs for durable goods, statistical agencies often use the acquisition approach; i.e., they simply allocate the cost of the durable good to the period when it was purchased. It would be useful to many users if, in addition to the acquisitions approach, statistical agencies would implement a variant of either the rental equivalence approach or the user cost approach for long lived consumer durables. Users can then decide which approach best suits their purposes. Any one of the three main approaches could be chosen as the approach that would be used in the "headline" CPI. ${ }^{6}$

\footnotetext{
${ }^{2}$ Others that have been pointed out include a) a relative rise in debt compared to income and net assets and an increase in leveraging, b) a sustained influx of capital and c) a lag in productivity increases compared to increases in asset values and debt.

${ }^{3}$ This is the so-called user cost and is calculated based on payments (including mortgage interest) and ownership-based taxes (fixed asset tax, etc.).

${ }^{4}$ Housing services represent $26.4 \%$ of the CPI for Tokyo's wards. Of this, $4.3 \%$ is private rent paid by tenants to owners while the remaining $19.4 \%$ is the imputed rent that the owner's of dwelling units pay for the services of their units. These imputed rents are the rents that owners would pay if they rented a dwelling unit of similar quality; i.e., the rental equivalence approach is used to compute imputed rents in the Japanese CPI.

${ }^{5}$ With regard to this point, refer to Goodhart (2001).

${ }^{6}$ See Diewert (2015) and Shimizu, Diewert, Nishimura and Watanabe (2012).
} 
The Statistics Bureau of Japan uses the rental equivalence approach to estimate housing rents for Owner Occupied Housing (OOH). However, Diewert (2015) indicated the following disadvantages of the rental equivalence approach;

- Homeowners may not be able to provide very accurate estimates for the rental value of their dwelling unit.

- On the other hand, if the statistical agency tries to match the characteristics of an owned dwelling unit with a comparable unit that is rented in order to obtain the imputed rent for the owned unit, there may be difficulties in finding such comparable units. Furthermore, even if a comparable unit is found, the rent for that unit may not be an appropriate opportunity cost for not renting the owned unit. ${ }^{7}$

- The statistical agency should make an adjustment to these estimated rents over time in order to take into account the effects of depreciation, which causes the quality of the unit to slowly decline over time (unless this effect is completely offset by renovation and repair expenditures).

- Care must be taken to determine exactly what extra services are included in the homeowner's estimated rent; i.e., does the rent include insurance, electricity and fuel or the use of various consumer durables in addition to the structure? If so, these extra services should be stripped out of the rent, since they are covered elsewhere in the consumer price index. ${ }^{8}$

Recently, the Statistics Bureau of Japan started to collect housing rent data from property management companies or owners to respond to first problem listed above. However, the characteristics of the owner occupied population of dwelling units could be quite different from the characteristics of the rental population. ${ }^{9}$ Thus in valuing the services of $\mathrm{OOH}$ in Japan, the current approach has some downward bias in that it does not adjust for quality declines due to depreciation (depreciation bias) and some possible bias due to the fact that the quality of rental units may be different from owned units that are thought to be comparable (quality adjustment bias).

\footnotetext{
${ }^{7}$ Diewert (2007) argued that the correct opportunity cost for valuing the services of an owned dwelling unit is the maximum of the amount the unit could rent for in the current rental market and the user cost of the dwelling unit since this represents the financial opportunity cost of tying up ones capital in the dwelling. In most countries, the user cost of a high end home is often approximately twice as high as its rental equivalence price. For less expensive owned homes, the user cost is usually much closer to the amount it could rent for. However, the situation in Japan could be quite different since Japan has experienced widespread asset deflation which did not occur in other developed countries.

${ }^{8}$ However, it could be argued that these extra services that might be included in the rent are mainly a weighting issue; i.e., it could be argued that the trend in the homeowner's estimated rent would be a reasonably accurate estimate of the trend in the rents after adjusting for the extra services included in the rent.

${ }^{9}$ For example, according to the 2013 Housing and Land Survey, the average floor space (size) of owneroccupied housing in Tokyo was 110.64 square meters for single-family house owner-occupied housing and 82.71 square meters for rental housing - a discrepancy of over 30 square meters. For condominiums, an even greater discrepancy exists: the floor space is 65.73 square meters for owner-occupied housing and 37.64 square meters for rental housing. Moreover, in addition to the difference in floor space between rented and owned units, the quality of the owned units tends to be higher than the rented units and these quality differences need to be taken into account.
} 
In addition to the above possible biases in using the rental equivalence approach to the valuation of the services of $\mathrm{OOH}$, there are differences between "contract rent" and "market rent". "Contract rent" refers to the rent paid by a renter who has a long term rental contract with the owner of the dwelling unit and "market rent" is the rent paid by the renter in the first period after a rental contract has been negotiated. In a "normal" economy which is experiencing moderate or low general inflation, typically market rent will be higher than contract rent. However, if there are rent controls or a temporary glut of rental units, then market rent could be lower than contract rent. In any case, it can be seen that if we value the services of an owner occupied dwelling at its current opportunity cost on the rental market, we should be using market rent rather than contract rent. ${ }^{10}$

It can be seen that there are many problems when we attempt to value the services of both owner occupied housing and of rented dwelling units. There have been many attempts in the literature that try to measure these possible biases. For example, Crone, Nakamura and Voith (2004) and Gordon and Goethem (2005) have pointed out the importance of addressing qualitative changes in rents and they estimated CPI bias by calculating hedonic-type quality-adjusted indexes. Crone, Nakamura and Voith (2006), focusing on changes in the estimation method of housing rents for CPIs, have analyzed the structure of these biases based on micro-data used to estimate CPI rents.

The rents used to estimate the cost of rented dwellings in the Japanese CPI is the aggregate of rents paid for rental accommodation. These rents include a combination of newly signed rental contracts and rollover contracts for existing tenants. It is appropriate to use both types of contract to measure the actual cost of rental housing (but of course, these rents should be quality adjusted for depreciation and other changes in quality). But it is not appropriate to use both types of contract to impute rents for owner occupied housing: only market rents should be used. It is known that price adjustments are basically not made for rollover contracts (i.e. renewed leases). As a result, it is to be expected that new contract rents determined freely by the market will diverge considerably from rollover contract rents.

Genesove (2003), based on a study using individual data from the American Housing Survey and survey research, has analyzed the stickiness of rents by dividing them into new contracts and rollover contracts.

In Japan, Shimizu, Nishimura and Watanabe (2010a) and Shimizu and Watanabe (2011) constructed a unique dataset using data from a housing listing magazine and a property management company to measure the extent of housing rent stickiness in the country and analyzed the micro-structure of rental adjustments.

In order to clear up remaining issues from Shimizu, Nishimura and Watanabe (2010a) and Shimizu and Watanabe (2011), this paper focuses on rent control bias or systemic bias in rental housing market and aims to construct a new dataset to re-estimate the

\footnotetext{
${ }^{10}$ On the other hand, contract rent is the "right" rental concept to use to value the cost of rental housing for the renter and it is the correct price to use to calculate the rental income of the owner of the rental unit.
} 
stickiness of housing rent in Japan and the implications of this stickiness for the valuation of the services of Owner Occupied Housing $(\mathrm{OOH})$. A second major objective of the present paper is to look at the effects of sampling the housing population: how much does accuracy of the housing component of the CPI decrease as the sampled population decreases?

\section{The Macroeconomic Analysis of Housing Rent}

\subsection{Data}

When attempting to conduct empirical research focusing on the housing market there are various difficulties involved in obtaining research data. This is because the organization and disclosure of information on housing lags behind other markets. Data is even more limited for the housing rental market. In both domestic and international research, analysis is conducted on a strongly hypothetical basis as is found in the studies by Shimizu, Nishimura and Watanabe (2010a) and Shimizu and Watanabe (2011).

Housing rent-related data may be broadly divided into two types. First, there are market rents, which are generated when a specific event occurs (i.e. a contract is created). These rents can be further broken down into rents based on new contracts when there is tenant turnover and rents based on new contracts for tenants who continue to reside in the same unit at the moment when the term of the previous contract ends. In general, the former are known as "new contracts" and the latter as "rollover contracts." Rents for the former are basically freely determined by the transaction market, while rents for the latter are determined based on systemic limitations such as the Act on Land and Building Leases. The other type of data is rent that continues to be paid on an ongoing basis. This rent is determined based on the new contract when a tenant arrives or the subsequent rollover contract and remains the same as long as no new event (i.e. contract) occurs. In this study, we have prepared these three types of data.

Data were provided by the company Recruit Co.Ltd. This is an insurance company that handles rental guarantees. As a result of handling insurance contracts at the time new rental contracts are drawn up, it has access to initial new rent amounts. In addition, since it provides compensation for rental defaults, it records the rental payment status each month and, by the same token, records the status of rental adjustments for rollover contracts.

The data are summarized in Table 1. It is limited to Tokyo's wards. We obtained data for 52,524 units covering the Tokyo ward area. In terms of the track record for rents recorded during the period covered here, there are 1,529,485 data items of which 36,832 were generated by new contracts and 41,117 were related to rollover contracts.

The average rent was $¥ 101,721$ and the standard deviation was $¥ 46,210$. Singleoccupancy rental housing was common with an average floor space of $32 \mathrm{~m}^{2}$. The average building age was 13.0 years while the average time to the closest station was 5.1 minutes and the shortest average time by train from the closest station to a terminal 
station on the Yamanote Line (Tokyo, Shinagawa, Shibuya, Shinjuku, Ikebukuro, Ueno) or Otemachi was 12.4 minutes, meaning that rental housing was concentrated in areas that are relatively convenient in terms of transportation.

If we compare the data by separating new contracts and rollover contracts, there are no major differences in average rent, floor space, building age, time to the closest station or average time to a terminal station, which is a major (and somewhat surprising result) of our study. ${ }^{11}$

\section{Table 1: Housing Rent Dataset}

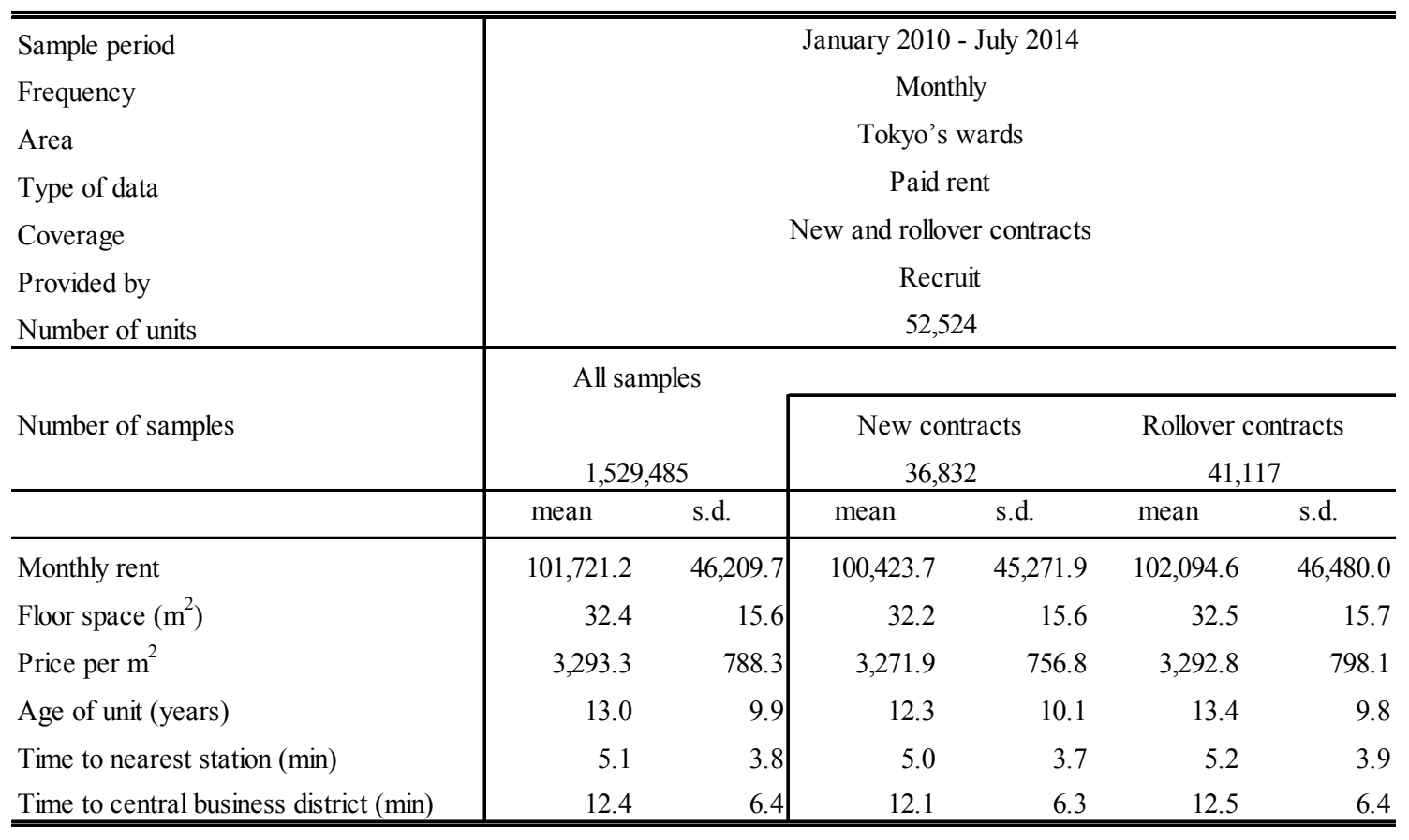

\subsection{Aggregate Rent Indexes using CPI Methodologies}

Using the created housing rent database, we analyzed macro trends in Tokyo ward area housing rents to check the sample selection bias compared with official CPI rent. In order to make this comparison on a quality adjusted basis, we created a quasi-official CPI rent index using our dataset.

\footnotetext{
${ }^{11}$ A possible explanation for this rent invariance result is that landlords hold rents constant even though the quality of the units deteriorates over time due to depreciation. Thus given that general inflation in Japan is zero or less, landlords are actually increasing constant quality rents by holding nominal prices constant. Thus landlords that are experiencing rollover or new contracts are happy enough to just charge the previous level of rents since they are actually achieving a hidden price increase in rents. Thus we do not expect this rental invariance result to hold in other countries that are not experiencing general deflation. However, it is also possible that this invariance result is due to quality adjustment bias; i.e., the above results are based on overall average prices and do not take into account quality differences between individual units. We will look at quality adjustment in section 3 below.
} 
Our quasi-official CPI rent index created an index using the same methodology as is used by the Ministry of Internal Affairs and Communications.

We also estimated an index using the same measurement method as the private rent index published by Statistics Bureau of Japan (hereafter referred to as CPI rent). CPI rent is measured based on a housing rent survey called the Retail Price Survey Rent Survey. This surveys the rent per month and total area of housing rented from private owners in municipalities covered by the Retail Price Survey. Nationwide, 1,221 districts have been selected as rental housing survey areas from census districts in survey municipalities by means of size-proportionate sampling. All households residing in housing rented from private owners in a given rental survey area are then asked their rent and total floor space. $^{12}$

There are 54 survey areas distributed throughout the Tokyo ward areas covered in this paper. ${ }^{13}$ Rental survey areas are assigned to three groups and surveyed one group at a time on a rotating basis so that a given rental survey area is surveyed every three months. ${ }^{14}$ In addition, the rental housing index is calculated using the total area and four categories based on the housing structure (small wooden housing, medium wooden housing, small non-wooden housing, and medium non-wooden housing) as the basic units. $^{15}$

In order to artificially measure CPI rent using our study data, we created panel data using the 53,746 units. We then performed the following calculations.

First, using all of the created panel data, we calculated an index using the CPI rent formula. This index was created from all observable paid rent data rather than sampling the survey areas (this shall be called the Non-Sampled Rent Index). ${ }^{16}$

Next, after performing sampling using the same method as the Ministry of Internal Affairs and Communications (MIC), we created an index (called the MIC Method

\footnotetext{
${ }^{12}$ This adds up to a total of around 28,000 households covered by the survey (see the 2013 Annual Report on the Retail Price Survey).

${ }_{11}^{13}$ Rental survey areas are distributed by survey municipality stratification.

${ }^{14}$ The most recent survey results are used for the rents of the groups that are not surveyed in a given month. In addition, if a surveyed unit becomes vacant, the most recent survey result will be used until it is next occupied. Moreover, samples are replaced by changing the rental survey areas every five years or so.

${ }^{15}$ Housing with a total floor space of less than $30 \mathrm{~m}^{2}$ is considered small and housing with a total floor space of $30 \mathrm{~m}^{2}$ or more is considered medium. The comparative price per $3.3 \mathrm{~m}^{2}$ is obtained by dividing the total number of rental homes by the total floor space and multiplying by 3.3. Indexes by basic unit category are calculated by dividing the comparative value by the baseline price, then the rent index is obtained by calculating weighted averages for the indexes by category.

${ }^{16}$ January 2010 was taken as the baseline point. For each of the four index types (small wooden housing, medium wooden housing, small non-wooden housing, and medium non-wooden housing), we divided the total rent by the total area and multiplied the result by 3.3 to obtain the comparison price per $3.3 \mathrm{~m}^{2}$. With regard to the total area categories, we divided them by taking $30 \mathrm{~m}^{2}$ as the reference value in the same manner as official indexes. For the housing structure, houses coded as "wooden" in the data were taken as wooden housing and all others were categorized as non-wooden housing. Indexes by category were calculated by dividing the comparative price by the baseline price. Since weights for aggregating the four category indexes have not been published, we calculated the weights based on the proportion of each category in Tokyo's ward areas in the 2009 Housing and Land Survey, in the same manner as the imputed rent for owned homes.
} 
Sampled Index). ${ }^{17}$ For the sampling, we first categorized all data by geographic neighborhood and divided them into hypothetical survey areas including roughly 30 to 60 units. ${ }^{18}$ Secondly, based on these artificially created survey areas, we sampled 54 survey areas in the same manner as the official index. Survey areas were pre-arranged so that they included at least one unit of each of the four survey categories, and at this time four survey areas were randomly selected from the prospective survey areas. Random sampling was performed for the remaining 50 survey areas. With regard to prices used in index calculation, the sampled 54 survey districts were sorted into three groups, each of which was used once every three months. ${ }^{19}$ Sampling was performed 200 times by means of sampling with replacement.

Figure 1 compares the Non-Sampled Rent Index using our dataset (the MIC Method Sampled Index estimated as described above) and the actual CPI rent in the Tokyo ward area. These indexes take the 2010 annual average as 1 .

First, comparing the Non-Sampled Rent Index and the MIC Method Sampled Index in conjunction with the error of $\pm 2 \sigma$ that occurs due to sampling, we can see that they are roughly the same. In other words, this confirms that in terms of the average value for sampling performed 200 times, the error due to sampling based on the MIC method is quite small.

Second, comparing the MIC Method Sampled Index and the actual CPI rent, we can see the same downward trend and actual CPI runs with in $\pm 2 \sigma$ of MIC Method Sampled Index. This is natural because the actual CPI's sample is quite a bit smaller than the created housing rent database. Using this result, it could be assumed that the created housing rent database is not so different from the sample of the actual CPI. But the chart also shows substantial differences between the two indexes: the MIC indexes are for the most part well below the corresponding actual CPI index. To verify that this difference is real, we examine our data more detail and in particular, we look at the weighting of the different types of house in the indexes.

\footnotetext{
${ }^{17}$ In terms of the categories, formula and weighting, the same method as for the Tokyo ward area described above was used but not all payment information was used; instead, the calculations used only hypothetically sampled data based on the same method as the MIC.

${ }_{18}$ The survey area size was based on the fact that the standard census survey area is set at around 50 households. We created 982 artificial survey areas.

${ }^{19}$ For prices in the groups that were not surveyed in a given month, the data for the most recent applicable month were used in the same manner as the official index. Additionally, in cases where rent was no longer paid due to a tenant departure, the most recent price was used until new payment information was recorded based on the arrival of the next tenant.
} 


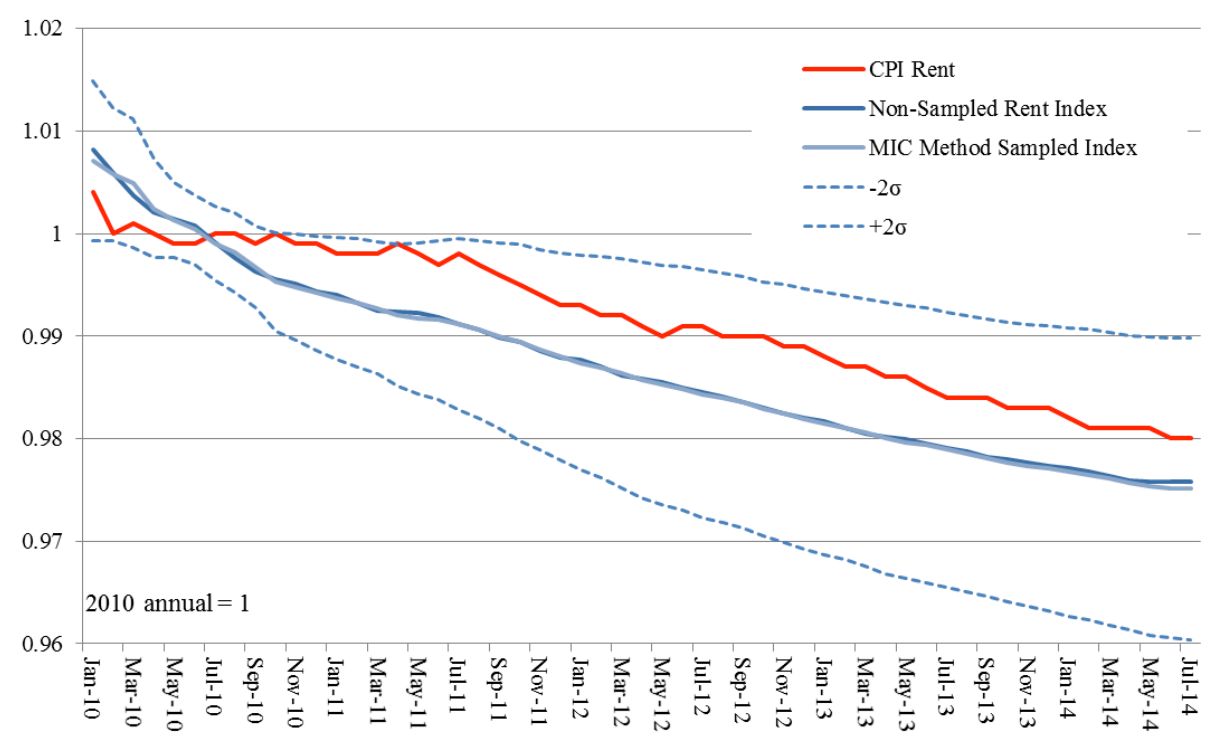

Figure 1: Comparison of Tokyo Ward Area Rent Indexes

Table 2: Dataset by Structure Type

\begin{tabular}{|c|c|c|c|c|c|c|c|c|c|c|}
\hline \multirow[t]{3}{*}{ Number of samples } & \multirow{2}{*}{\multicolumn{2}{|c|}{ All samples }} & & & & & & & & \\
\hline & & & \multirow{2}{*}{\multicolumn{2}{|c|}{$\begin{array}{l}\text { Small wooden housing } \\
\qquad \begin{array}{c}121,784 \\
(0.080)\end{array}\end{array}$}} & \multicolumn{6}{|c|}{ Medium wooden housingSmall non-wooden housin̨̧̨ledium non-wooden housi } \\
\hline & \multicolumn{2}{|c|}{$\begin{array}{c}1,529,485 \\
(1.000)\end{array}$} & & & $\begin{array}{l}22,9 \\
(0.0\end{array}$ & & $\begin{array}{l}776, \\
(0.5\end{array}$ & & $\begin{array}{l}608 \\
(0.3\end{array}$ & \\
\hline \multirow[t]{2}{*}{ Number of units } & \multicolumn{2}{|c|}{$\begin{array}{l}52,524 \\
(1.000)\end{array}$} & \multicolumn{2}{|c|}{$\begin{array}{c}4,106 \\
(0.078)\end{array}$} & \multicolumn{2}{|c|}{$\begin{array}{c}719 \\
(0.014)\end{array}$} & \multicolumn{2}{|c|}{$\begin{array}{l}27,045 \\
(0.515)\end{array}$} & \multicolumn{2}{|c|}{$\begin{array}{l}20,654 \\
(0.393)\end{array}$} \\
\hline & mean & s.d. & mean & s.d. & mean & s.d. & mean & s.d. & mean & s.d. \\
\hline Monthly rent & $101,721.2$ & $46,209.7$ & $58,487.2$ & $11,548.7$ & $87,521.4$ & $25,354.3$ & $79,801.6$ & $17,760.7$ & $138,879.6$ & $50,387.7$ \\
\hline Floor space $\left(\mathrm{m}^{2}\right)$ & 32.4 & 15.6 & 18.8 & 4.6 & 39.9 & 9.1 & 22.3 & 3.7 & 47.7 & 13.7 \\
\hline Price per $\mathrm{m}^{2}$ & $3,293.3$ & 788.3 & $3,228.5$ & 746.9 & $2,200.4$ & 459.9 & $3,587.0$ & 610.0 & 2,972.6 & 842.0 \\
\hline Age of unit (years) & 13.0 & 9.9 & 19.1 & 10.9 & 17.7 & 10.0 & 11.6 & 9.2 & 13.4 & 9.9 \\
\hline Time to nearest station (min) & 5.1 & 3.8 & 7.5 & 4.4 & 9.3 & 6.2 & 4.5 & 3.0 & 5.3 & 4.2 \\
\hline Time to city center (min) & 12.4 & 6.4 & 15.5 & 6.8 & 18.0 & 6.0 & 11.5 & 5.9 & 12.7 & 6.6 \\
\hline
\end{tabular}

The weights for the four categories estimated in this study are 0.16 for small wooden housing, 0.07 for medium wooden housing, 0.38 for small non-wooden housing and 0.38 for medium non-wooden housing. These weights are estimated from the 2008 Housing and Land Survey.

Table 2 provides a summary by category of the study data. As one can see from the table, the proportions for wooden housing diverge from their weights $(7.8 \%$ for small wooden housing and only $1.4 \%$ for medium wooden housing). In other words, significant weight is applied to the movement of the component prices where the calculations are based on small samples. In addition, the 2013 average for rents paid for privately owned housing in Tokyo’s ward area in the Retail Prices Survey was $¥ 2,654$ which is lower than the average in our data. Based on these facts, we may presume that distributional 
differences exist between the housing rent data used in this study and the samples used in the actual CPI. Thus the average quality of the housing units in the housing rent CPI may be different from the average quality of the housing units in our constructed MIC indexes.

\subsection{Hedonic estimation for housing rent}

In this section, we estimate a hedonic constant quality index using new housing rent data.

Shimizu, Nishimura and Watanabe (2010a), Shimizu and Watanabe (2011) indicated that difference between new housing rent and paying rent impacts rent price indexes. They mentioned that paying rent occasionally changes during the contract period. In the opposite direction, new housing rent reflects changes in the market. As a consequence of this difference, significant difference is caused between two price indexes.

Let us begin with a hedonic price index. Suppose that we have the price and propertycharacteristics data of houses, pooled for all periods $t=1,2, \ldots, T$, and that the number of data samples in period $t$ is $n_{t}$. Then, a standard hedonic price index is produced from the following house-price estimation model:

$$
\ln R_{i t}=\beta_{t} x_{i t}+\varepsilon_{i t}
$$

where $R_{i t}$ is the rent of house $i$ in period $t, \beta_{t}$ is a vector of parameters associated with residential property characteristics, $x_{i t}$ is a vector of property characteristic for house $i$ in period $t$, and $\varepsilon_{i t}$ is an error term, which consists of time dummies and iid disturbance $\left(\varepsilon_{i t} \equiv \alpha+\delta_{t}+v_{i t}\right.$ and $\left.v_{i t} \sim N\left(0, \sigma_{v}^{2}\right)\right)$. The standard hedonic price index is then constructed from the time dummies.

The house characteristics coefficient vector $\beta_{t}$ is usually assumed to be constant over time. However, Shimizu, Takatsuji, Ono and Nishimura (2010) and Shimizu, Nishimura and Watanabe (2010b) modified the standard hedonic model given by equation (1) so that the parameters associated with the attributes of a house are allowed to change over time. Structural changes in the Japanese housing market have two important features. First, they usually occur only gradually, triggered, with a few exceptions, by changes in regulations by the central and local governments. Such gradual changes are quite different from "regime changes" discussed by econometricians such as Bai and Perron (1998) in which structural parameters exhibit a discontinuous shift at multiple times. Second, the changes in parameters reflect structural changes at various time frequencies. Specifically, as found by Shimizu, Nishimura and Watanabe (2010b), some changes in parameters are associated with seasonal changes in housing market activity.

To allow for a gradually changing characteristics coefficient vector, we estimate the model defined by equations (1) for periods $t=1, \ldots, \tau$, where $\tau<T$ represents the window width. As usual, set the first time dummy variable $\delta_{1} \equiv \mathrm{d}_{1}{ }^{*} \equiv 1$ and denote the

remaining estimated time parameters for this first regression by $\mathrm{d}_{2}{ }^{*}, \ldots, \mathrm{d}_{\mathrm{r}}{ }^{*}$. These 
parameters are exponentiated to define the sequence of house price indexes $P_{\mathrm{t}}$ for the first $\tau$ periods; i.e., $P_{\mathrm{t}} \equiv \exp \left[\mathrm{d}_{\mathrm{t}}{ }^{*}\right]$ for $t=1,2, \ldots, \tau$. Thus the first $\tau$ price indexes, $P_{1}, \ldots, P_{r}$, are determined by this initial rolling window regression. Then a new $\tau$ period regression model using the data for the periods $2,3, \ldots, \tau+1$ can be repeated and a new set of estimated time parameters, $\mathrm{d}_{2}{ }^{2^{*}} \equiv 1, \mathrm{~d}_{3}{ }^{2^{*}}, \ldots, \mathrm{d}_{\mathrm{r}+1}{ }^{2^{*}}$ can be obtained. The new price levels $P_{\mathrm{t}}^{2}$ for periods 2 to $\tau+1$ can be defined as $P_{\mathrm{t}}^{2} \equiv \exp \left[\mathrm{d}_{\mathrm{t}}^{2 *}\right]$ for $\mathrm{t}=2,3, \ldots, \tau+1$. The final price index for period $\tau+1$ is determined as $P_{\tau+1} \equiv\left[P_{\tau+1}^{2} / P_{\tau}^{2}\right] P_{\tau}$; i.e., the price level for period $\tau$, $P_{\tau}$ (obtained from the first rolling window regression), is updated by the ratio of the price indexes for period $\tau+1$ to period $\tau$ that we obtained from the second rolling window regression, $P_{\tau+1}^{2} / P_{\tau}^{2}$. Obviously, this process of adding the data of the next period to the rolling window regression while dropping the data pertaining to the oldest period in the previous regression can be continued. The focus in the Shimizu, Takatsuji, Ono and Nishimura (2010) paper was on determining how the structural parameters changed as the window of observations changed. ${ }^{20}$

In this paper, we run a rolling window regression using our information on new contract housing rents with window length $T=12$. Table 3 indicates the estimation results of rolling hedonic models.

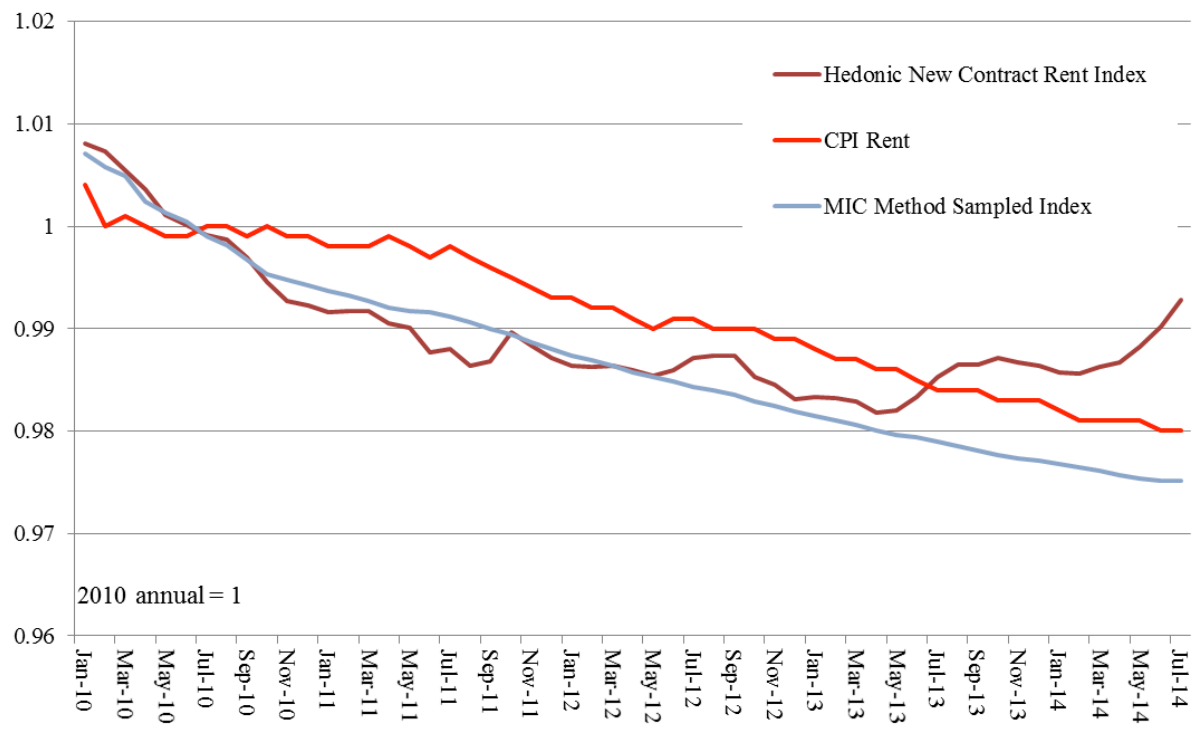

Figure 2: Comparison of actual CPI and estimated indexes.

Figure 2 shows estimated result of our Hedonic new contract rent index and the CPI rent index and the MIC index described in section 2.2. During 2010, the Hedonic index follows the MIC Method Sampled Index but it starts to deviate starting at November 2010. At first, it ran below the MIC Method Sampled Index but starting in the middle of 2012, it moved substantially above both the MIC and CPI indexes. This increase in rents may reflect the effect of changes in economic policy; i.e., the introduction of "Abenomics" and the attempt to end deflation.

\footnotetext{
${ }^{20}$ They called their method the Overlapping Period Hedonic Housing Model (OPHM).
} 
Table 3: Estimation Result of Hedonic Model of New Housing Rent

\begin{tabular}{|c|c|c|c|c|c|c|}
\hline $\begin{array}{l}\text { Estimation } \\
\text { Window }\end{array}$ & $\begin{array}{l}\text { Floor } \\
\text { space }\end{array}$ & $\begin{array}{c}\text { Age of } \\
\text { building }\end{array}$ & $\begin{array}{l}\text { Time to } \\
\text { nearest } \\
\text { station }\end{array}$ & $\begin{array}{c}\text { Commutin } \\
\text { g time to } \\
\text { CBD }\end{array}$ & $\begin{array}{l}\text { Adjusted } \\
\qquad \mathbf{R}^{2}\end{array}$ & $\begin{array}{c}\text { Number of } \\
\text { obs ervations }\end{array}$ \\
\hline $201001-201012$ & 0.0188 & -0.0109 & -0.0087 & -0.0058 & 0.917 & 17,697 \\
\hline $201002-201101$ & 0.0188 & -0.0109 & -0.0088 & -0.0058 & 0.916 & 16,707 \\
\hline 201003 - 201102 & 0.0188 & -0.0109 & -0.0089 & -0.0059 & 0.917 & 15,670 \\
\hline $201004-201103$ & 0.0188 & -0.0110 & -0.0090 & -0.0059 & 0.917 & 14,504 \\
\hline $201005-201104$ & 0.0188 & -0.0110 & -0.0092 & -0.0058 & 0.916 & 13,303 \\
\hline $201006-201105$ & 0.0189 & -0.0111 & -0.0094 & -0.0058 & 0.915 & 11,684 \\
\hline $201007-201106$ & 0.0189 & -0.0112 & -0.0096 & -0.0060 & 0.914 & 10,667 \\
\hline 201008 - 201107 & 0.0190 & -0.0114 & -0.0097 & -0.0062 & 0.916 & 9,942 \\
\hline 201009 - 201108 & 0.0189 & -0.0115 & -0.0095 & -0.0065 & 0.918 & 9,099 \\
\hline $201010-201109$ & 0.0190 & -0.0114 & -0.0099 & -0.0065 & 0.919 & 8,346 \\
\hline $201011-201110$ & 0.0191 & -0.0113 & -0.0104 & -0.0067 & 0.922 & 7,571 \\
\hline 201012 - 201111 & 0.0191 & -0.0113 & -0.0105 & -0.0066 & 0.924 & 6,698 \\
\hline $201101-201112$ & 0.0191 & -0.0114 & -0.0104 & -0.0067 & 0.924 & 6,490 \\
\hline $201102-201201$ & 0.0192 & -0.0114 & -0.0104 & -0.0067 & 0.927 & 6,446 \\
\hline $201103-201202$ & 0.0192 & -0.0113 & -0.0101 & -0.0065 & 0.927 & 6,485 \\
\hline $201104-201203$ & 0.0192 & -0.0113 & -0.0102 & -0.0067 & 0.927 & 6,564 \\
\hline 201105 - 201204 & 0.0194 & -0.0113 & -0.0099 & -0.0071 & 0.928 & 6,664 \\
\hline $201106-201205$ & 0.0194 & -0.0112 & -0.0096 & -0.0075 & 0.929 & 6,782 \\
\hline $201107-201206$ & 0.0194 & -0.0110 & -0.0095 & -0.0074 & 0.927 & 6,788 \\
\hline 201108 - 201207 & 0.0193 & -0.0110 & -0.0096 & -0.0071 & 0.925 & 6,880 \\
\hline 201109 - 201208 & 0.0193 & -0.0109 & -0.0098 & -0.0068 & 0.923 & 6,887 \\
\hline $201110-201209$ & 0.0191 & -0.0109 & -0.0096 & -0.0071 & 0.922 & 6,913 \\
\hline $201111-201210$ & 0.0191 & -0.0110 & -0.0096 & -0.0072 & 0.922 & 6,920 \\
\hline $201112-201211$ & 0.0192 & -0.0110 & -0.0094 & -0.0074 & 0.922 & 6,988 \\
\hline $201201-201212$ & 0.0191 & -0.0109 & -0.0091 & -0.0075 & 0.922 & 6,963 \\
\hline $201202-201301$ & 0.0189 & -0.0109 & -0.0091 & -0.0072 & 0.918 & 6,968 \\
\hline $201203-201302$ & 0.0188 & -0.0109 & -0.0091 & -0.0076 & 0.918 & 7,000 \\
\hline $201204-201303$ & 0.0188 & -0.0108 & -0.0093 & -0.0076 & 0.918 & 7,012 \\
\hline $201205-201304$ & 0.0187 & -0.0109 & -0.0097 & -0.0073 & 0.917 & 6,939 \\
\hline $201206-201305$ & 0.0186 & -0.0109 & -0.0098 & -0.0071 & 0.916 & 6,785 \\
\hline $201207-201306$ & 0.0186 & -0.0110 & -0.0098 & -0.0071 & 0.917 & 6,725 \\
\hline $201208-201307$ & 0.0186 & -0.0110 & -0.0098 & -0.0073 & 0.918 & 6,526 \\
\hline $201209-201308$ & 0.0186 & -0.0110 & -0.0097 & -0.0075 & 0.918 & 6,409 \\
\hline 201210 - 201309 & 0.0187 & -0.0110 & -0.0097 & -0.0074 & 0.918 & 6,260 \\
\hline $201211-201310$ & 0.0186 & -0.0110 & -0.0098 & -0.0073 & 0.916 & 6,179 \\
\hline 201212 - 201311 & 0.0186 & -0.0110 & -0.0099 & -0.0073 & 0.916 & 6,028 \\
\hline 201301 - 201312 & 0.0187 & -0.0110 & -0.0105 & -0.0075 & 0.915 & 5,869 \\
\hline 201302 - 201401 & 0.0189 & -0.0109 & -0.0107 & -0.0078 & 0.918 & 5,718 \\
\hline 201303 - 201402 & 0.0191 & -0.0108 & -0.0110 & -0.0077 & 0.918 & 5,530 \\
\hline 201304 - 201403 & 0.0190 & -0.0108 & -0.0109 & -0.0075 & 0.919 & 5,389 \\
\hline $201305-201404$ & 0.0191 & $-\mathbf{0 . 0 1 0 7}$ & -0.0109 & -0.0075 & 0.918 & 5,288 \\
\hline $201306-201405$ & 0.0192 & -0.0106 & -0.0112 & -0.0077 & 0.918 & 5,273 \\
\hline 201307 - 201406 & 0.0191 & -0.0105 & -0.0114 & -0.0077 & 0.916 & 5,206 \\
\hline 201308 - 201407 & 0.0192 & -0.0104 & -0.0113 & -0.0079 & 0.915 & 5,225 \\
\hline Average & 0.0190 & -0.0110 & -0.0099 & -0.0070 & 0.9196 & 7,863 \\
\hline
\end{tabular}




\section{The Micro-Analysis of Rents}

\subsection{The Frequency of Rent Adjustments}

In this section we will a conduct further analysis at the micro level. We will begin by measuring the stickiness of rent. What we will measure here is the probability that rent will not change during a given year (i.e. the percentage of all units for which the rent does not change), which may be expressed as $\operatorname{Pr}\left(\Delta R_{i t}=0\right)$.

Rents are changed at the times when rental contracts are revised, which means either 1) there is tenant turnover or 2) the rental contract is renewed even though there is no tenant turnover. $I_{i t}{ }^{N}$ is a variable that takes a value of 1 if unit turnover occurs and a new contract is agreed between the landlord and the new tenant with regard to unit $i$ in period $t$, and 0 otherwise. Meanwhile, $I_{i t}{ }^{R}$ takes a value of 1 if a rollover contract is agreed between the existing tenant and the landlord with regard to unit $i$ in period $t$, and 0 otherwise. In addition, the rent level for unit $i$ in period $t$ is denoted by $R_{i t}$, while $\Delta R_{i t} \equiv R_{i t}-R_{i t-1}$ shows the rental adjustment amount at the time the contract is agreed. Therefore, the probability that there will be a change in rent $\left(\operatorname{Pr}\left(\Delta R_{i t}=0\right)\right)$ can be expressed as follows:

$$
\begin{aligned}
\operatorname{Pr}\left(\Delta R_{i t}=0\right)= & {\left[1-\operatorname{Pr}\left(I_{i t}{ }^{N}=1\right)-\operatorname{Pr}\left(I_{i t}^{R}=1\right)\right]+\operatorname{Pr}\left(\Delta R_{i t}=0 \mid I_{i t}{ }^{N}=1\right) \operatorname{Pr}\left(I_{i t}{ }^{N}=1\right) } \\
& +\operatorname{Pr}\left(\Delta R_{i t}=0 \mid I_{i t}{ }^{R}=1\right) \operatorname{Pr}\left(I_{i t}^{R}=1\right)
\end{aligned}
$$

Let us look at the terms on the right side of Eq. (2) one at a time. First, as seen in Table 1, among the total of 52,524 units, 36,832 new contracts occurred during the entire sample period. However, this does not mean that the rent was changed for all units for which new contracts were signed. This is examined in Table 4. The upper part of this table shows the proportion of rents that decreased, remained stable and increased among those units for which a new contract occurred within the sample period. Looking at the sample period as a whole, the rent was kept stable for $86.2 \%$ of the 36,832 new contracts. Meanwhile, the lower part of the table shows the same figures for rollover rents. Rollover contracts were renewed for 41,117 of the units during the sample period but the rent remained stable for $98.0 \%$ of these.

Taking these numbers as given, the first term on the right side of Eq. (2), [1- $\operatorname{Pr}\left(I_{i t}{ }^{N}=1\right)$ $\left.\operatorname{Pr}\left(I_{i t}{ }^{R}=1\right)\right]$, is 0.526 , which shows that there was neither a new contract or contract renewal for $52.6 \%$ of the units. Moreover, even if a new contract did occur, there was a 0.862 probability that the rent would be kept at the same amount, which means that the second term on the right side of Eq. (2), $\operatorname{Pr}\left(\Delta R_{i t}=0 \mid I_{i t}{ }^{N}=1\right) \operatorname{Pr}\left(I_{i t}{ }^{N}=1\right)$, is 0.193. Similarly, even if a rollover contract occurred, the rent did not change for $95.8 \%$ of units, so the third term on the right side of Eq. (2), $\operatorname{Pr}\left(\Delta R_{i t}=0 \mid I_{i t}{ }^{R}=1\right) \operatorname{Pr}\left(I_{i t}{ }^{R}=1\right)$, is 0.245 . Based on the 
above, the sum of the three terms on the right side of Eq. (2) is 0.964 , so the proportion of units for which rent did not change in one year, $\left(\operatorname{Pr}\left(\Delta R_{i t}=0\right)\right)$, is $96.4 \%$.

\section{Table 4: The Nominal Rigidity of Rent}

\begin{tabular}{cccccc}
\hline \hline & Rent decreased & Rent unchanged & Rent increased & Total & (Rent change) \\
\cline { 1 - 3 } Changes accompanying & 4,181 & 31,737 & 914 & 36,832 & 5,095 \\
new contracts & $(0.114)$ & $(0.862)$ & $(0.025)$ & $(0.224)$ & $(0.138)$ \\
Changes accompanying & 641 & 40,284 & 192 & 41,117 & 833 \\
rollover contracts & $(0.016)$ & $(0.980)$ & $(0.005)$ & $(0.250)$ & $(0.020)$ \\
\cline { 1 - 3 } Total contract changes & 4,822 & 72,021 & 1,106 & 164,356 & 5,928 \\
& $(0.029)$ & $(0.438)$ & $(0.007)$ & $(1.000)$ & $(0.036)$ \\
\hline \hline
\end{tabular}

How should we interpret these results showing that the rent did not change in a given year for $96.4 \%$ of units and, conversely, did change for $3.6 \%$ of units? According to Genovese (2003), who performed similar calculations for the U.S., the proportion of units for which rent did not change in a given year in the U.S. was $29 \%$, with the rent being changed for the remaining 71\%. Hoffmann and Kurz-Kim (2006), meanwhile, performed similar calculations for Germany, finding that the proportion of units for which rent did not change in a given year was $78 \%$ while it was changed for the remaining $22 \%$. Compared to these figures, the $3.6 \%$ probability that rent will be changed in Japan is extremely low, representing a mere 1/20th of the U.S. figure and 1/6th of the German figure. It can therefore be said that rents in Japan have an extremely high degree of rigidity compared to the U.S. and Germany.

Figure $3 \mathrm{a}$ and $3 \mathrm{~b}$ look at changes over time in nominal rent rigidity. Given that rollover contracts occur once every two years as a rule, they reduce the frequency of new contracts. Additionally, if we look at changes in the probability that rents will not change, gradual changes can be seen over time, but when aggregated by month, they remain stable at roughly $85 \%$.

On the other hand, the stickiness of rollover rents (i.e. the probability that the rent will not change) hovers at around 95\%. In other words, this shows that while the probability of a change in rent accompanying a new contract changes based on seasonality, there is no change in the probability of rent changing for rollover contracts, which remains uniform. To put it another way, we may consider that neither new contract rent nor rollover contract rent change depend on the contract renewal time and instead occur randomly in conjunction with contract changes.

Next, we looked at the magnitude of rental changes when a rent renewal event occurs (Figure 4). Specifically, we observed the probability density for the rental comparison before and after rent revision $\left(\Delta R_{i t}=R_{t} / R_{t-1}\left|I_{i t}{ }^{N}=1, \Delta R_{i t}=R_{t} / R_{t-1}\right| I_{i t}{ }^{R}=1\right)$ excluding events in which the rent was kept at the same level. First, looking at the rent renewal range for new 
contracts, the scope of rent renewal was from $-30 \%$ to $+10 \%$. For rollover contracts, on the other hand, upward revisions were relatively few in comparison to new contracts. Even if there was a rental revision, the amount was more or less the same as before and it was most likely to be a downward adjustment. In other words, it is rare for rent to be increased for a rollover contract. If we look at the extent of decreases in rent, there was a certain likelihood of new contract rents decreasing by as much as $30 \%$, whereas for rollover contracts, it was kept at around $20 \%$. Thus, for rollover contracts, not only is the probability that the rent changes extremely low, but if a change does occur, the scope of the change will be small.

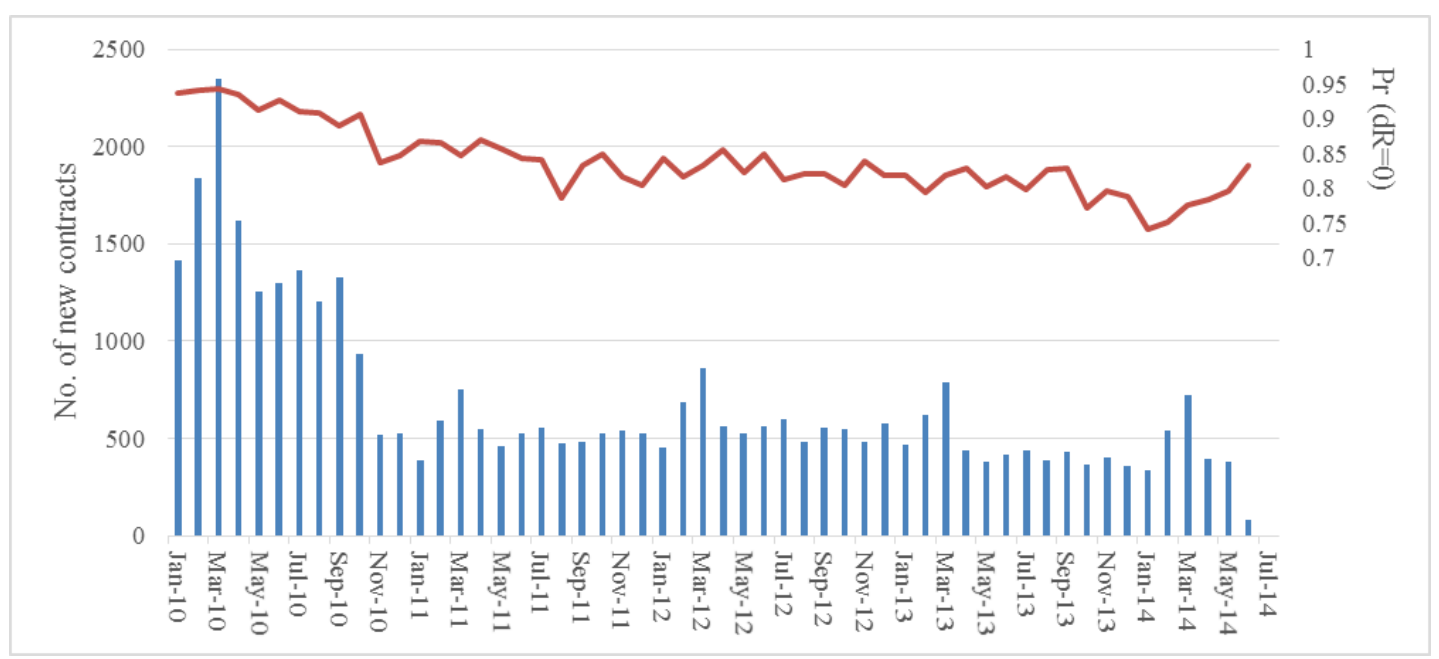

a) New Contracts

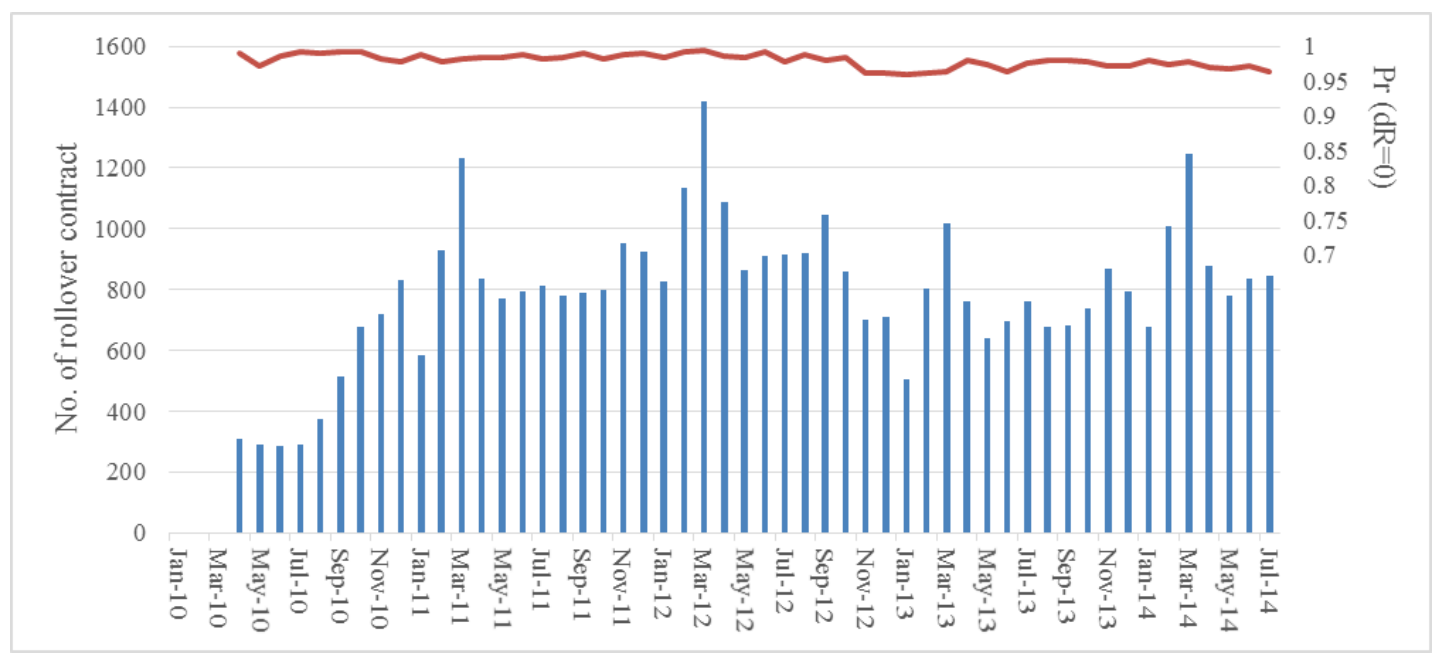

b) Rollover Contracts

Figure 3: Monthly Changes in Nominal Rigidity of Rent 


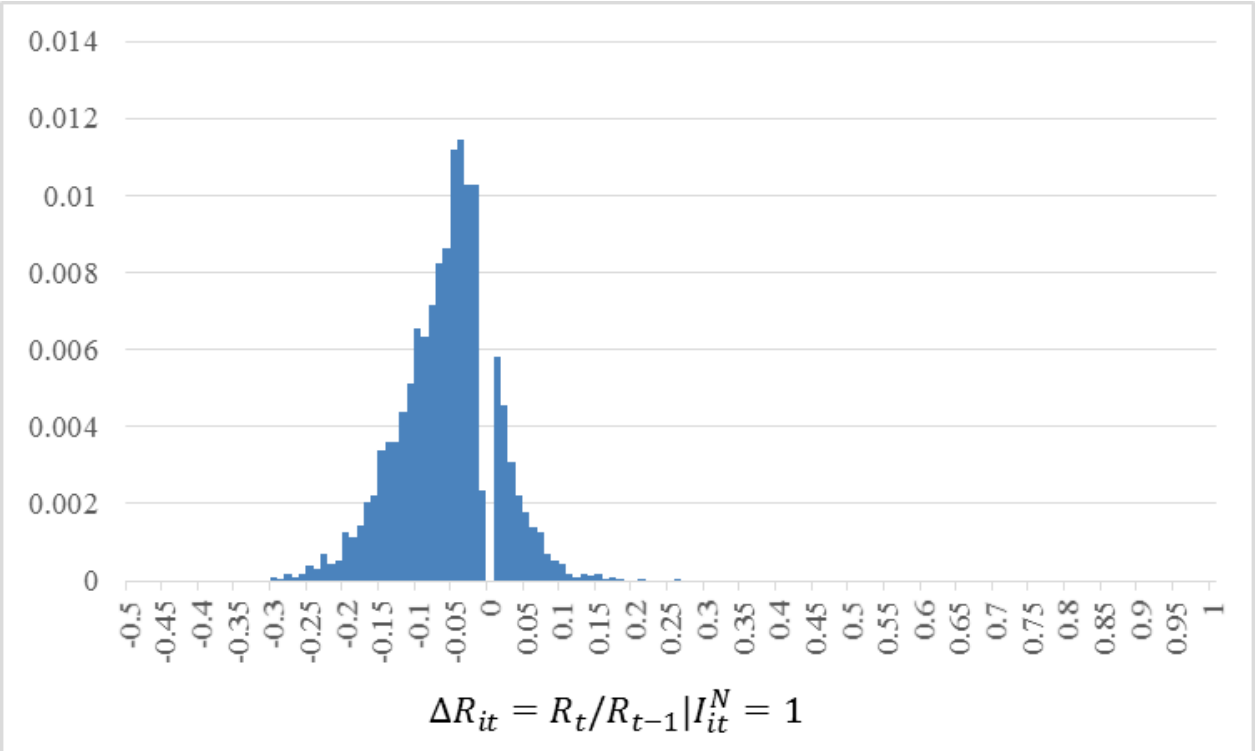

a) New Contracts

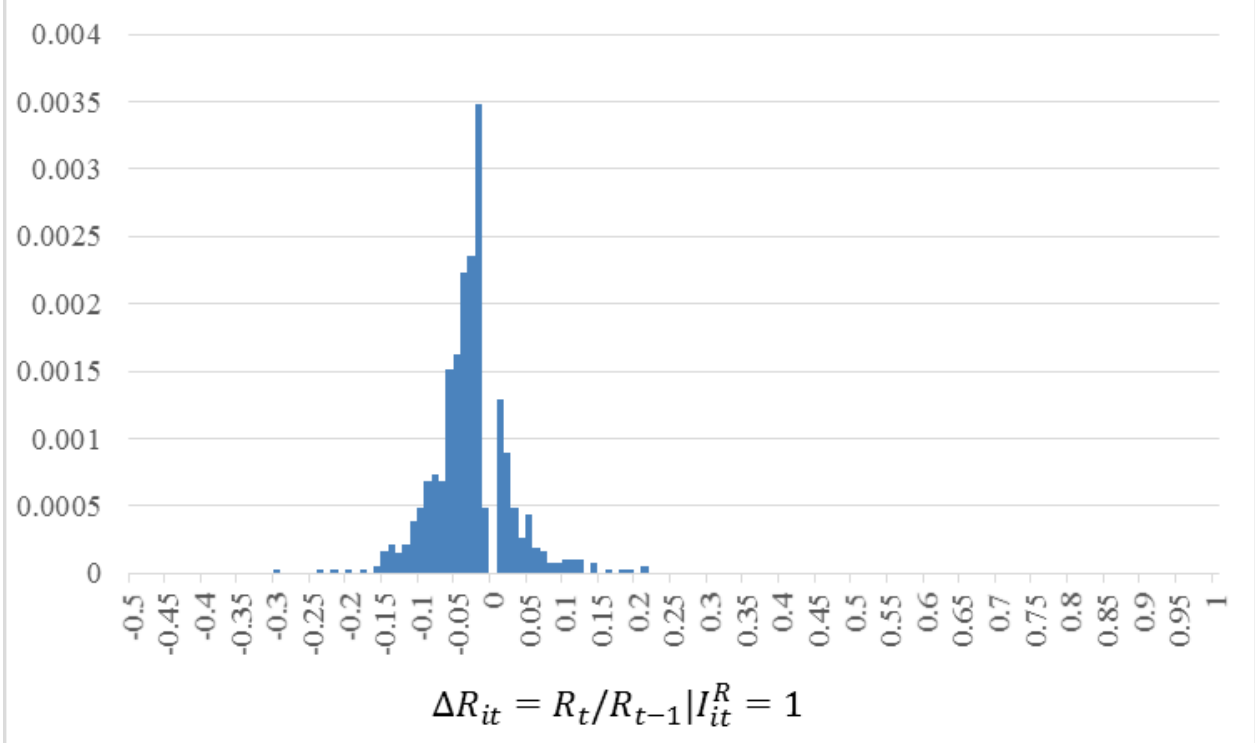

b) Rollover Contracts

Figure 4: Rent Revision Range Density Distribution

In addition, for both new contract rent revisions and rollover contract rent revisions, the revision probability decreases in the vicinity of 0 . In other words, this shows that rent revisions are made within a certain range and it is rare for minor changes to occur. This suggests the presence of a so-called "menu cost."

Since the probability of a rent revision event occurring is extremely low, we may also consider that once such an event does occur, the range of the change will be relatively large compared to other goods and services. For example, new contract revisions occur as 
a result of finding new tenants via listing magazines, the Internet, etc., and if a new tenant cannot be found within a certain period of time, the search will be continued by lowering the amount of rent. In such cases, we may consider it unlikely that the price revision will be a minor one since the change must be enough to justify the time and cost involved in running advertisements and implementing the price change.

\subsection{Time-Dependent versus State-Dependent Adjustments}

In a given month, the rent for a given unit will be revised while the rent for another unit will not be revised. What is the reason for this difference? There are two theories. The first is that there is a target rent level for different units, and when they diverge significantly from that level, the rent will be revised. According to this theory, the more the rent for a given unit diverges from the target level, the higher the probability that it will be revised. The extent to which the current rent diverges from the target rent is called the "price gap," and using this term, we can say that the probability of rent revision depends on the price gap. This theory is referred to as "state-dependent" pricing. In contrast, there is another theory which says that the probability of rent revision does not depend on the price gap at all. In other words, the probability of rent revision does not change based on how close or how far the current rent is from the target level. This is known as "non-state dependent" or "time-dependent" pricing. Below, we will investigate whether rent revision is state-dependent or time-dependent using the method of Caballero and Engel (2007).

We will define the target rent level as $R_{i t}{ }^{*}$ which we will assume is determined based on the following formula:

$$
\Delta \log R_{i t}{ }^{*}=\Delta \xi_{t}+v_{i t}
$$

Here, $\Delta \xi_{t}$ represents aggregate shocks (shocks common to all units) and $v_{i t}$ idiosyncratic shocks. The price gap is defined as the difference between the current rent and target rent level-i.e. $X_{i i} \equiv \log R_{i t}-\log R_{i t}{ }^{*}$. The probability that the rent will be revised based on this condition alone is expressed by the following equation:

$$
\Lambda(x) \equiv \operatorname{Pr}\left(\Delta R_{i} \neq 0 \mid X_{i t}=x\right)
$$

This $\Lambda(x)$ function is called the adjustment hazard function. It was first proposed by Caballero and Engel (1993). If the probability $\operatorname{Pr}\left(\Delta R_{i t} \neq 0\right)$ changes depending on the state variable $x$, it is state-dependent, and if it does not depend on $x$, it is time-dependent. 
Using the above material, it is possible to calculate how the average rent level of all units responds to aggregate shocks.

$$
\Delta \log R_{i t}\left(\Delta \xi_{t}\right) \equiv \int \Delta \log R_{i t}\left(\Delta \xi_{t}, x\right) h(x) d x=-\int\left(x-\Delta \xi_{t}\right) \Lambda\left(x-\Delta \xi_{t}\right) h(x) d x
$$

Here, $h(x)$ is the cross-section distribution of the state variable $x$. Differentiating Eq. (5) based on aggregate shock after integrating $i$ yields the following equation:

$$
\lim _{\Delta \xi t \rightarrow 0} \Delta \log R_{t} / \Delta \xi_{t}=\int \Lambda(x) h(x) d x+\int x \Lambda(x)^{\prime} h(x) d x
$$

The left side of this equation indicates how much the average rent for all units responds to aggregate shocks and is similar to an impulse response function. If the average rent for all units is adjusted rapidly in response to aggregate shocks, this value will be high. In this sense, the left side of Eq. (6) represents the elasticity of rent. According to Eq. (6), the elasticity of rent defined in this way is decided by two factors. The first term on the right side is the average rent adjustment probability for all units. Naturally, if the rent revision probability for all units is high, the average value will be high as well and rent will therefore be elastic. However, according to Eq. (6), the elasticity of rent is not just defined by this because a second term exists on the right side. In order to explain the significance of the second right-hand term, let us consider a case where $\Lambda(x)$ does not depend on $x$-i.e. a time-dependent case. In this case, since $\Lambda^{\prime}(x)$ is 0 , the second right-hand term is also 0 . However, in a state-dependent case, $\Lambda^{\prime}(x)$ is not 0 , so the second right-hand term will not be 0 either. As shown by Caballero and Engel (2007), the second right-hand term is positive in many state-dependent models. The value of the second right-hand term is determined by how large $\Lambda^{\prime}(x)$ is (how much it differs from 0). Caballero and Engel (2007) refer to the first right-hand term as the intensive margin and the second right-hand term as the extensive margin.

In order to apply the above analysis framework to rent, we will first define $\Lambda(x)$ for housing rent as follows:

$$
\begin{aligned}
\Lambda(x)=\operatorname{Pr}\left(\Delta R_{i t} \neq 0 \mid I_{i t}{ }^{N}=1, x_{i t}=x\right) \operatorname{Pr}\left(I_{i t}{ }^{N}=1, x_{i t}=x\right) \\
+\operatorname{Pr}\left(\Delta R_{i t} \neq 0 \mid I_{i t}{ }^{R}=1, x_{i t}=x\right) \operatorname{Pr}\left(I_{i t}{ }^{R}=1, x_{i t}=x\right)
\end{aligned}
$$

As can be understood from the right side, the rent revision probability function $\Lambda(x)$ is composed of four conditional probabilities. It is the sum of the product of the probability of a state-dependent new contract occurring $\left(\operatorname{Pr}\left(I_{i t}{ }^{N}=1, x_{i t}=x\right)\right)$ and the probability of the rent revision based on that contract $\left(\operatorname{Pr}\left(\Delta R_{i} \neq 0 \mid I_{i t}{ }^{N}=1, x_{i t}=x\right)\right)$ and the product of the 
probability of a rollover contract occurring $\left(\operatorname{Pr}\left(I_{i t}{ }^{R}=1, x_{i t}=x\right)\right)$ and the probability of the rent changing based on that $\left(\operatorname{Pr}\left(\Delta R_{i t} \neq 0 \mid I_{i t}{ }^{R}=1, x_{i t}=x\right)\right)$.
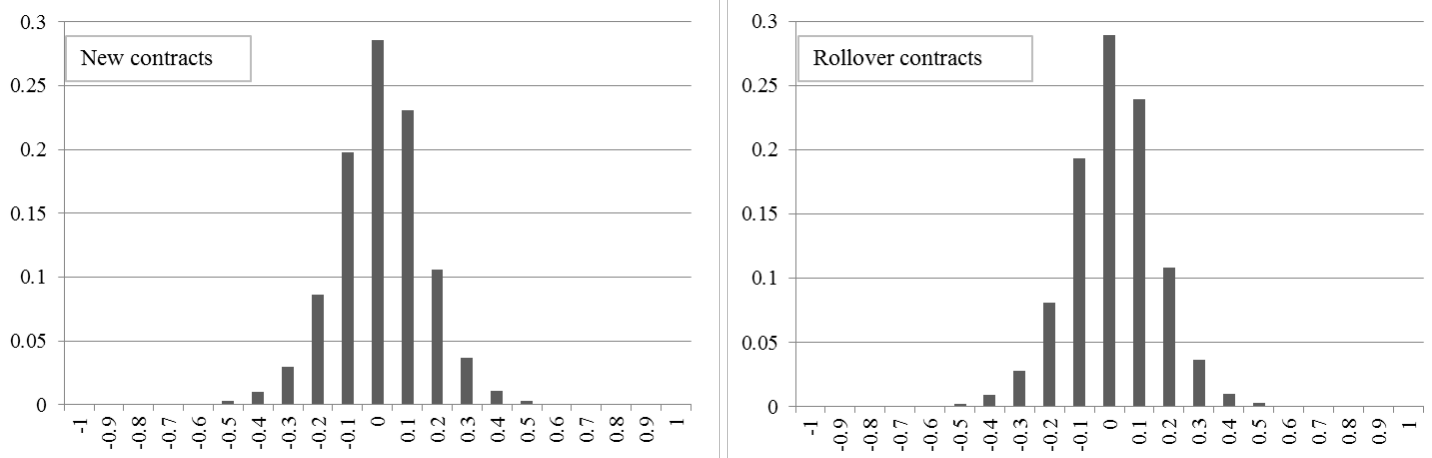

Figure 5: Price Gap Distributions
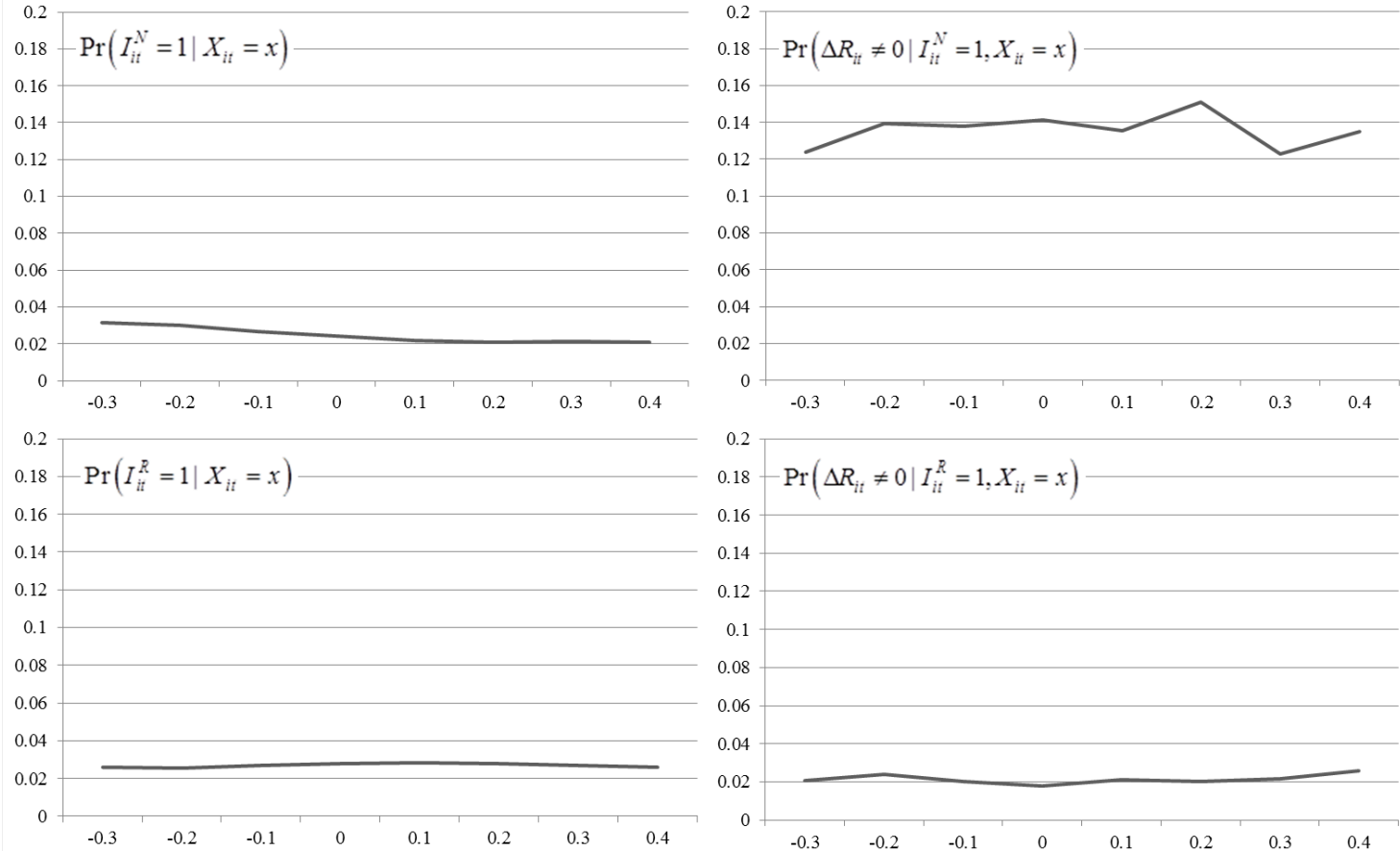

Figure 6: State-Dependency

Figure 5 looks at the distribution of the price gap $x .^{21}$ For both new contracts and rollover contracts, it falls within the range of roughly -0.3 to +0.4 . In other words, at its highest, the rate of divergence from the appropriate rent level is around 30\%. Given this distribution for $x$, Figure 6 shows the calculated four conditional probabilities in Eq. (7).

\footnotetext{
${ }^{21}$ The target rent $\mathrm{R}^{*}$ was estimated based on a hedonic method in the same manner as was used by Shimizu, Nishimura and Watanabe (2010a). With regard to the choice of hedonic model, we chose the Rolling Hedonic Model proposed by Shimizu, Ono, Takatsuji and Nishimura (2010).
} 
First, the probability of a new contract occurring $\left(\operatorname{Pr}\left(I_{i t}{ }^{N}=1, x_{i t}=x\right)\right)$ in the upper left of Figure 6 is more or less level at around 0.025 per month (approx. 30\% per year). In other words, this is not dependent on the price gap. We may consider tenant turnover as occurring when moving becomes necessary due to circumstances such as changing job, getting married, giving birth, etc., and this shows that these circumstances occur independently of the price gap. No tendency for people to move due to their current rent being higher than the appropriate level can be observed. The probability of a rollover contract occurring $\left(\operatorname{Pr}\left(I_{i t}{ }^{R}=1, x_{i t}=x\right)\right)$ shown in the lower left of Figure 6 is also more or less level and not dependent on the price gap. We can see that contract renewals occur once every two years or so regardless of the price gap.

Next, if we look at the probability that rent will change based on a new contract $\left(\operatorname{Pr}\left(\Delta R_{i} \neq 0 \mid I_{i t}{ }^{N}=1, x_{i t}=x\right)\right)$ in the upper right of Figure 6, it is more or less flat, but when one examines it in detail, there is a slight upward slope and there is dip at 0.3 . What this means is that if tenant turnover occurs in units where the current paid rent is higher than the appropriate level (market rate), the probability of the rent being changed is higher than it is in cases of tenant turnover in units where the current rent is not higher. This suggests that when searching for new tenants for units where the paid rent is higher than the market rent, it will not be possible to find one unless a lower rent is set. Finally, looking at the probability that the rent will change based on rollover contracts $\left(\operatorname{Pr}\left(\Delta R_{i} \neq 0 \mid I_{i t}{ }^{R}=1, x_{i t}=x\right)\right)$ in the lower right, one can see that it is similar to new contracts: it slopes upward when the price gap exceeds the level of 0.3 .

Compared to Shimizu, Nishimura and Watanabe (2010a)'s estimation results, a number of differences can be observed in these results. The reason for this may be that the distribution of price gap $x$ varies. In Shimizu, Nishimura and Watanabe (2010a), the bubble period that occurred from the 1980s through the 1990s is included in the sample, so $x$ changed significantly due to abrupt fluctuations in $R^{*}$. As a result, despite the strong inherent stickiness of the rental market, a tendency for paid rents to approach market rents was observed. However, Shimizu and Watanabe (2011) obtained more or less the same results in analysis using large management company data. In this sense, a certain robustness can be seen in terms of Japanese rents' rigidity and price gap dependency.

Table 5 summarizes the above estimation results. It shows at a glance how the four probabilities indicated on the left side are dependent on the price gap $x$. On the one hand, we can see that the probability $\operatorname{Pr}\left(I_{i t}{ }^{N}=1, x_{i t}=x\right)$ tends to slightly decrease somewhat as the price gap $x$ grows bigger, whereas the probability $\operatorname{Pr}\left(I_{i t}{ }^{R}=1, x_{i t}=x\right)$ does not depend on the price gap and remains more or less fixed. Meanwhile, the probability $\operatorname{Pr}\left(\Delta R_{i} \neq 0 \mid I_{i t}{ }^{N}=1\right.$, $x_{i t}=x$ ) that the rent will be changed when there is tenant turnover becomes larger when the price gap $x$ is positive compared to when it is negative. This suggests that when the 
current rent exceeds the market rate, rent will be adjusted at the time of tenant turnover. Finally, the probability $\operatorname{Pr}\left(\Delta R_{i t} \neq 0 \mid I_{i t}{ }^{R}=1, x_{i t}=x\right)$ also becomes larger when the price gap $x$ is positive compared to when it is negative.

As shown in Eq. (7), it is possible to calculate $\Lambda(x)$ using the four probabilities in Table 5. The results of the actual calculations are shown in the row for $\Lambda(x)$ in Table 5 . $\Lambda(x)$ is more or less flat, with no relation to $x$. We can consider this as showing that $\Lambda(x)$ mostly does not depend on $x$. The level of $\Lambda(x)$ stays between 0.003 and 0.005 , and this, as shown by the definition of $\Lambda(x)$ in Eq. (6), is an indicator representing the elasticity of rent. It signifies that in a given year, the rent will be changed for $4.1 \%$ to $5.5 \%$ of all units.

Here, a key point is how much the intensive margin and extensive margin contribute to the rent revision probability. If we actually calculate how much each contributes in line with Eq. (6), the formula is as follows ${ }^{22}$ :

$\int \Lambda(x) h(x) d x=0.0500, \int x \Lambda(x)^{\prime} h(x) d x=0.0081, \lim _{\Delta \xi t \rightarrow 0} \Delta \log R_{t} / \Delta \xi_{t}=0.0581$

In other words, Caballero and Engel (2007)'s price elasticity indicator on the left side of Eq. (6) is 0.0621. If we separate this into two, following the example of Eq. (6), the intensive margin is 0.0081 and the extensive margin is 0.0082 . From this we can see that the extensive margin is extremely small, accounting for only $14 \%$ of Caballero and Engel (2007)'s price elasticity indicator. We may consider it as being practically 0 . The fact that the extensive margin is 0 means that rent revision is not state-dependent but timedependent.

\footnotetext{
${ }^{22}$ Comparing the analysis results in Table 5 to Table 3 in Shimizu, Nishimura and Watanabe (2010a), the value of $\Lambda(x)$ differs considerably. According to Table 3 in Shimizu, Nishimura and Watanabe (2010a), the value of $\Lambda(x)$ is around 10\%, which is double the result in this paper. When we look at the source of this difference, we find that it can largely be explained by the difference in probability $\operatorname{Pr}\left(\Delta R_{i t} \neq 0 \mid I_{i t}{ }^{N}=1, x_{i t}=x\right)$. In this paper, the probability that rent will be changed when there is tenant turnover is approximately $20 \%$, but in Shimizu, Nishimura and Watanabe (2010a) it is around 70\%. This may reflect a fundamental difference in the nature of the buildings covered by the analysis. It may also reflect the difference in the analysis periods. Specifically, Shimizu, Nishimura and Watanabe (2010a)'s sample period includes the bubble period. That was a time when major fluctuations in the market occurred rapidly, so we may consider that landlords and tenants both behaved in a way that led to rent being changed when a new contract was agreed.
} 
Table 5: Summary of Estimation Results

\begin{tabular}{ccccc}
\hline \hline & $x \in[-0.4,-0.2)$ & $x \in[-0.2,0.0)$ & $x \in[0.0,0.2)$ & $x \in[0.2,0.4)$ \\
\hline $\operatorname{Pr}\left(I_{i t}^{N}=1 \mid X_{i t}=x\right)$ & 0.035 & 0.029 & 0.023 & 0.021 \\
$\operatorname{Pr}\left(I_{i t}^{R}=1 \mid X_{i t}=x\right)$ & 0.006 & 0.026 & 0.028 & 0.027 \\
$\operatorname{Pr}\left(\Delta R_{i t} \neq 0 \mid I_{i t}^{N}=1, X_{i t}=x\right)$ & 0.131 & 0.134 & 0.138 & 0.137 \\
$\operatorname{Pr}\left(\Delta R_{i t} \neq 0 \mid I_{i t}^{R}=1, X_{i t}=x\right)$ & 0.015 & 0.022 & 0.020 & 0.021 \\
$\Lambda(x)$ & 0.005 & 0.004 & 0.004 & 0.003 \\
\hline$h(x)$ & 0.039 & 0.569 & 0.337 & 0.047 \\
\hline \hline
\end{tabular}

\section{Re-estimation of the CPI}

We have seen in the previous sections that the probability of individual rent adjustments is very low and that it depends little on price imbalances. These two facts imply that price flexibility in terms of the impulse response function is low, thus causing the CPI for rent to respond only slowly to aggregate shocks. Shimizu, Nishimura and Watanabe (2010a) simulated the estimation of the CPI depending on the change of stickiness and examined the impact. In this paper, we simplify their model: we assume that the (imputed) prices for owner-occupied housing services are very flexible and thus never deviate from the corresponding market prices. Based on this assumption, we replace the imputed rent for owner-occupied housing in the CPI by our estimate of the market rent $\mathrm{R}^{*}$. And making a second assumption, we replace the imputed rent for $\mathrm{OOH}$ by our estimate of the depreciation adjusted rent R-age. A certain amount of depreciation occurs over rent properties year by year. We estimate R-age by multiplying the imputed rent of $\mathrm{OOH}$ by this depreciation rate as a rise of prices. The depreciation rate is estimated as $-0.011^{23}$ from Table 3.

Figure 8 shows $\mathrm{R}^{*}$, R-age and actual CPI in 2000:1Q-2014:4Q. This treatment is perfectly consistent with the rental equivalent approach which "values the services yielded by the use of a dwelling by the corresponding market value for the same sort of dwelling for the same period of time" (Diewert and Nakamura, 2009).

Figure 7 shows clearly that actual CPI rent continues to decrease but contrary to the Hedonic estimate, $\mathrm{R}_{\mathrm{t}}^{*}$ increased $6 \%$ from 2006 to 2008. After that, it drops sharply due to the Financial Crisis but it turns up again after starting the great easing caused by "Abenomics". On the other hand, depreciation adjusted R-age lies between $\mathrm{R}^{*}$ and the

\footnotetext{
${ }^{23}$ The average of coefficient $\beta$ for "Age of Building" in Table 2 is -0.011 . It means that the depreciation rate is minus 1.1 percent per year.
} 
actual CPI. And it is clear that if we adjust the depreciation, the drop in hte index has practically disappeared and it stays almost flat.

Figure 8 shows how these changes in rents impacts the CPI. First we look at $\mathrm{R}^{*}$. During the IT bubble in the early 2000 's, it led to a $0.4 \%$ difference in the inflation rate. From 2006 to 2008 (just before the Financial Crisis), the largest difference in the inflation rate is $0.5 \%$ and the average difference is about $0.3 \%$.

Focusing from Jan. 2013 onward (the period that the Bank of Japan announced a new price stability target and started a monetary expansion, there is a difference starting from Q4 of 2013: a $0.2 \%$ difference repeatedly appeared during this period. This difference is an important signal because the Hedonic index $\mathrm{R}_{\mathrm{t}}{ }^{*}$ turns up while the CPI rent index continues to decrease. It implies that the difference from actual CPI seems to increase because the Hedonic index $\mathrm{R}_{\mathrm{t}}{ }^{*}$ seems to be increasingly apt to increase.

Next we turn into age adjusted CPI rent, R-age. This index exhibits a mild decline over the sample period as opposed to the actual CPI, which declined much more. This result shows clearly that the depreciation adjusted rent modifies the downward bias of actual rents as measured by the CPI. But it is also based on sticky rent prices so it hardly reflects the effect of asset price fluctuation.

The above analysis show that how the CPI treats owner-occupied housing rents can make a big difference to the CPI. Hence the evaluation of the effectiveness of "Abenomics" in eliminating deflation depends to a large extent on the valuation of the services of owner-occupied housing.

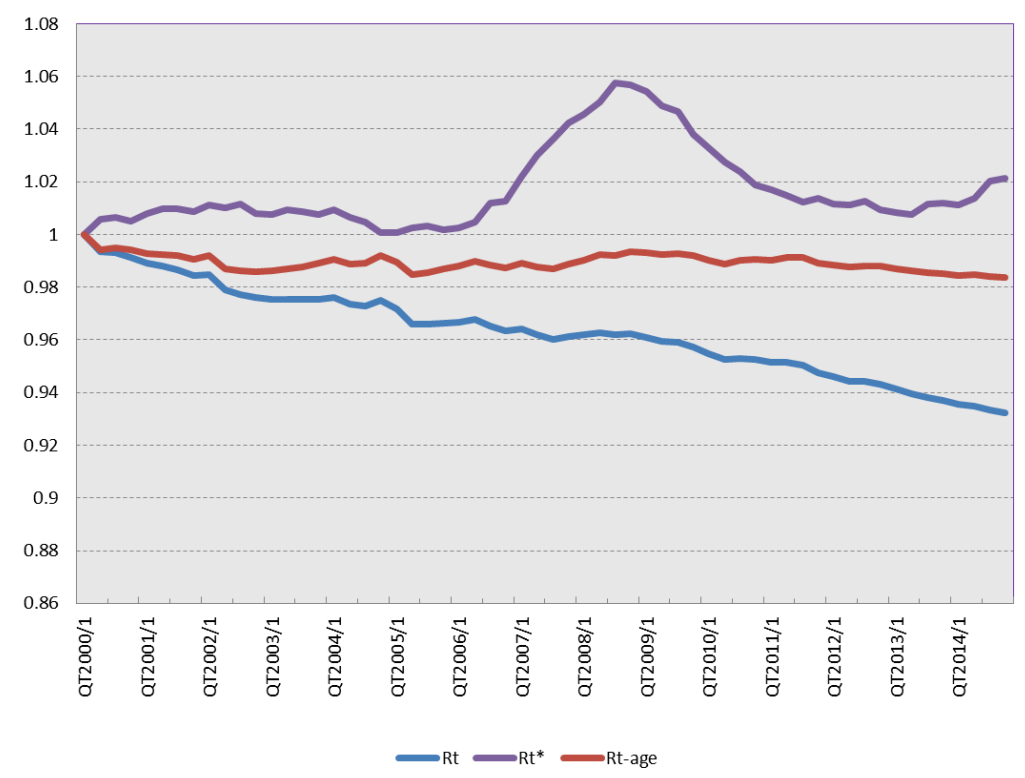

Figure 7: Hedonic estimate Rt*, Rt-age and Actual CPI 


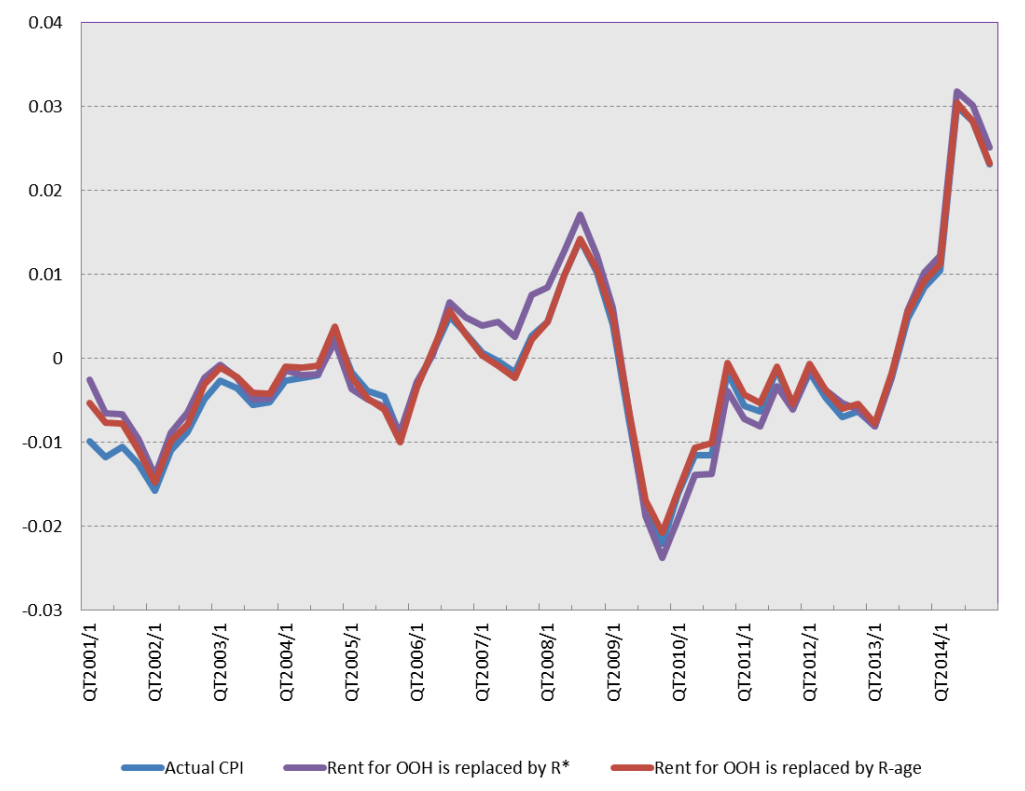

Figure 8: Reestimates of CPI inflation under Rent for $\mathrm{OOH}$ replaced by $\mathrm{Rt}^{*}$ and Rage

\section{Conclusion}

Goods and services prices, as represented by consumer price indexes and the like, have not changed all that much in response to fluctuations in asset prices. In particular, there were no major change in goods and services prices even during the significant rise in asset prices that was one of the factors leading to the global financial crisis and subsequent decline in such prices. This lack of correlation means that business cycle management via financial policy is difficult.

Accordingly, focusing on rents, which are an important connecting point between asset market and goods and services market, we attempted to measure housing rent for Japan. Our research has two major implications for the construction of a price index for rented properties in Japan.

Our first major point is that the Japanese rent index has a downward bias due to the neglect of depreciation. In other words, the actual CPI has a strong downward bias due to the neglect of this "aging depreciation". We calculated depreciation rate for housing rent in Japan using hedonic regression techniques and it is approximately 1.1 percent per year. ${ }^{24}$ In addition to this depreciation bias problem, housing rent has another problem in CPI: namely the strong rigidity of price changes.

\footnotetext{
${ }^{24}$ The depreciation rate is expressed as a fraction of property value, which includes the value of land. Thus the structure (net) depreciation rate is actually higher than $1.1 \%$ per year.
} 
Thus our second major result in this paper showed that, while rents based on new contracts change in an elastic manner, actual paid rents change only gradually, even when market shocks occur. In other words, average market rents, which are representative of consumer prices, have a strong tendency to change in a random manner, independently of changes in rents determined freely by the market. This rent stickiness means that consumer prices as a whole fluctuate gradually. As a result, when it comes to financial policy and the like, agile policy management targeting only goods and services price indicators is not possible.

Under this situation, the importance of developing economic statistics (residential price indexes) that are able to accurately capture fluctuations in residential property prices as an asset price has been pointed out (Diewert, 2007) and the United Nations, IMF, OECD, BIS, and ILO have jointly put together international handbook on residential property price indexes. ${ }^{25}$ Many countries in Europe are constructing these types of indexes and from March 2015, a Residential Property Price Index has been published on an experimental basis for the past 3 years in Japan.

By developing a Residential Property Price, it becomes possible to construct user cost price indexes and acquisition cost price indexes for $\mathrm{OOH}$ and these alternative $\mathrm{OOH}$ indexes can be compared with their rental equivalence counterparts. On the other hand, the fact that such an index has been developed does not mean that it is possible to respond immediately to asset bubbles or subsequent recessions. However, considering past experiences in which policy implementation delays caused significant economic confusion, it is strongly hoped that the development of asset price-related statistics will make it possible to achieve more flexible policy management.

Going forward, it will likely be necessary to clarify the relationship between asset price fluctuations and rent fluctuations. There are also still many significant questions to be addressed in the future regarding this issue.

\section{References}

[1] Bai, J., and P. Perron (1998), "Estimating and testing linear models with multiple structural changes", Econometrica 66, 47-78.

[2] Caballero, R. J., and E. Engel (1993), "Microeconomic Rigidities and Aggregate Price Dynamics", European Economic Review, Vol. 37, pp. 697-717.

[3] Caballero, R. J., and E. Engel (2007), "Price Stickiness in Ss models: New interpretations of old results", Journal of Monetary Economics, Vol. 54, pp. 100-121.

[4] Calvo, G (1983), "Staggered Prices in a Utility-Maximizing Framework", Journal of Monetary Economics, Vol. 12, pp. 383-398.

\footnotetext{
${ }^{25} \mathrm{http}$ //epp.eurostat.ec.europa.eu/portal/page/portal/hicp/methodology/residential_property_price_indices
} 
[5] Crone, T. M., L.Nakamura and R.Voith (2004), "Hedonic Estimates of the cost of housing services: Rental and owner-occupied units", Price Federal Reserve of Bank of Philadelphia Working Papers, No. 04-22.

[6] Crone, T. M., L. Nakamura and R.Voith (2006), "The CPI for Rents: A Case of Understated Inflation", Price Federal Reserve of Bank of Philadelphia Working Papers, No. 06-7.

[7] Diewert, W. E (2007), "The Paris OECD-IMF Workshop on Real Estate Price Indexes: Conclusions and Future Directions", University of British Columbia Discussion Paper 07-1.

[8] Diewert, W.E (2015), INDEX NUMBER THEORY AND MEASUREMENT, ECONOMICS 580: LECTURE NOTES at University of British Columbia.

[9] Diewert, W.E. and A. O. Nakamura (2009), Accounting for Housing in a CPI, chapter 2, pp. 7-32 in W.E. Diewert, B.M. Balk, D. Fixler, K.J. Fox and A.O. Nakamura (2009), PRICE AND PRODUCTIVITY MEASUREMENT: Volume 1 -- Housing. Trafford Press.

[10] Diewert, W. E. and C. Shimizu (2013), "Residential Property Price Indexes for Tokyo," Discussion Paper 13-07, Vancouver School of Economics, University of British Columbia. Macroeconomic Dynamics, forthcoming.

[11] Diewert, W. E. and C. Shimizu (2014), "Alternative Approaches to Commercial Property Price Indexes for Tokyo," Discussion Paper 14-08, Vancouver School of Economics, University of British Columbia.

[12] Diewert, W. E., K. Fox and C. Shimizu (2014), "Commercial Property Price Indexes and the System of National Accounts," Discussion Paper 14-09, Vancouver School of Economics, University of British Columbia, forthcoming in the Journal of Economic Surveys.

[13] Genesove, D (2003), "The Nominal Rigidity of Apartment Rents", The Review of Economics and Statistics, Vol. 85 (4), pp. 844-853.

[14] Goodhart, C (2001), "What Weight Should be Given to Asset Prices in Measurement of Inflation?" The Economic Journal, Vol. 111, (No. 472), pp. 335-356.

[15] Gordon, R. J and Todd van Goethem (2005), "A Century of Housing Shelter Prices: Is there a downward bias in the CPI", NBER Working Paper, No. 11776.

[16] Hoffmann, J and Jeong-Ryeol Kurz-Kim (2006), "Consumer price adjustment under the microscope: Germany in a period of low inflation", Deutsche Bundesbank Discussion Paper Series 1: Economic Studies, No. 16. 
[17] Reinhart C. M and Kenneth S. Rogoff (2008), "This Time Is Different: A Panoramic View of Eight Centuries of Financial Crises,” NBER Working Paper No. W13882.

[18] Shimizu, C and T. Watanabe (2011), "Nominal Rigidity of Housing Rent", Financial Review, Vol. 106, No. 1, pp 52-68.

[19] Shimizu, C, K.G. Nishimura and T. Watanabe (2010a), "Residential Rents and Price Rigidity: Micro Structure and Macro Consequences", Journal of the Japanese and International Economics, Vol. 24, No. 1, pp 282-299.

[20] Shimizu, C, K.G. Nishimura and T. Watanabe (2010b), "House Prices in Tokyo: A Comparison of Repeat-sales and Hedonic Measures," Journal of Economics and Statistics, Vol. 230(6), 792-813.

[21] Shimizu, C., W.E. Diewert, K.G. Nishimura and T.Watanabe (2012), "The Estimation of Owner Occupied Housing Indexes using the RPPI: The Case of Tokyo," RIPESS (Reitaku Institute of Political Economics and Social Studies) Working Paper,No.50.(presented at: Meeting of the Group of Experts on Consumer Price Indexes Geneva, 30 May - 1 June 2012(UNITED NATIONS)).

[22] Shimizu, C, H. Takatsuji, H. Ono and K. G. Nishimura (2010), "Structural and Temporal Changes in the Housing Market and Hedonic Housing Price Indexes," International Journal of Housing Markets and Analysis, Vol. 3, No. 4, pp. 351-368. 